\title{
LATTICE TOWER DYNAMIC RESPONSE CALCULATION TO HUMAN INDUCED LOADS: CASE STUDY
}

\author{
Liga Gaile', Ivars Radinsh ${ }^{2}$ \\ ${ }^{1,2}$ Department of Structural Mechanics, Faculty of Construction, Riga Technical University, \\ Azenes st. 16, LV-1048 Riga, Latvia \\ E-mail:1Liga.Gaile_1@rtu.lv(correspondingauthor); ${ }^{2}$ Ivars.Radins@rtu.lv
}

\begin{abstract}
A step by step algorithm of light-weight lattice tower dynamic response calculation method to typical human induced time varying horizontal loads is presented in this work for the first time. The developed algorithm of the method is based on the researches presented in the previous works of the authors on the subject. The calculation method itself is based on the generally accepted design processes for low frequency structures when it is convenient to consider the maximum level of the resonant response that can be induced by a person under repeated footfall and to limit it to the acceptable level. The algorithm was applied to find theoretically the peak acceleration amplitudes of vibration on an actual 36m high light-weight lattice observation tower in Jurmala, Latvia with eccentric structural configuration. The theoretically obtained results showed good agreement with the experimental data found in previous experiments. The calculation algorithm could be considered as a useful tool for the structural designers when undertaking the design of light-weight slender public observation towers.
\end{abstract}

Keywords: lattice tower, observation tower, dynamic response, human induced loads, footfall, walking harmonic, fundamental frequency, peak acceleration, comfort level

\section{Introduction}

Nowadays the serviceability criteria often govern contemporary structural design. Structures such as lightweight pedestrian bridges, slender floors, grandstands and long span stairs are prone to vibrations caused by human activities (Živanović et al. 2005, Feldmann et al. 2004, Catbas et al. 2004, Dougill et al. 2008, Kerr, Bishop 2001). Lattice tower type structures are also remarkably flexible, low in damping and light in weight that results in structures that are susceptible to human induced vibrations (Gaile 2013). Traditionally for such type of structures dynamic analysis is performed to evaluate only wind induced vibrations and effects on the structure.

But in areas with a low seismicity and relatively low wind loads the human induced dynamic loads are determinative in a slender light-weight observation tower design in case there is a requirement to satisfy serviceability criteria - comfort of the structure users.

Human walking induces dynamic time varying forces which have components in vertical, lateral and longitudinal directions that are due to accelerating and decelerating of the mass of its body (Gronley, Perry 1984).

In the case of pedestrian bridges, vibrations are mainly induced in a transverse direction and are basically caused by the pedestrian lateral component of load. Vibrations of the pedestrian bridges are relatively well studied; consequently the design recommendations have been developed to ensure an adequate pedestrian comfort. Unlike pedestrian bridges, the observation towers are subjected to both a pedestrian load transverse and a longitudinal component. But there is a lack of understanding and inadequate design information of the building codes, regarding the slender tower dynamic response to human induced loads.

An algorithm of the methodology for calculation of maximum response of structure to typical human induced loads is presented in the paper. This could be a useful material for the structural engineers working in the industry and undertaking the design of public observation towers as any other design information regarding this subject is not available yet. The possibility to predict the vibration amplitudes of the lattice observation towers gives the designers confidence about the dynamic behaviour of structure in service and therefore allows to design more interesting structures from an architectural point of view.

\section{Methodology of tower response calculations}

The developed algorithm of the methodology for calculation of maximum response of structure to typical human induced loads is based on the experimental and theoretical investigations published in previous papers of the authors (Gaile 2013, Gaile, Radinsh 2013, Gaile, Radinsh 2012a, Gaile, Radinsh 2012b). The verification of the developed methodology is performed by comparing the theoretically and experimentally obtained results of the structures maximum response and presented in the next section as a case study.

From the theoretical point of view, according to the generally accepted design processes for low frequency structures it is convenient to consider the maximum level of the resonant response that can be induced by a person under repeated footfall and to limit it to the acceptable level. Based on this principle the following procedure can be used to determine whether the designed lattice observation tower fulfils the serviceability requirement: acceptable comfort level of users of the structure.

\section{Step 1: To determine the input parameters}

Input parameters needed for calculation are geometry of the structure and structural elements, dynamic parameters of the observation tower (fundamental and natural frequencies, mode shapes, tower self-weight, stiffness and damping ratio), mean weight of the visitors (recommended $G=746 N$ ), limit on number of the tower 
visitors at once to be verified, number of subsequent "successive steps" $n$ (a footfall coinciding with the natural frequency of the structure).

If the structure is generally symmetric and has uniform stiffness and mass distribution along its height, it is possible to use the analytical method presented in (Gaile, Radinsh 2013) to determine the mode shapes and corresponding natural frequencies. Otherwise use of FEM model is appropriate.

\section{Step 2: To determine the most possible design situations}

Response to human movement induced loads should be assessed when the fundamental frequency of a lattice observation tower is less than $3.3 \mathrm{~Hz}$. Lattice structures with higher fundamental frequencies are usually too stiff to be considerably excited by typical human induced dynamic walking loads.

Theoretical pacing frequency $f_{p}$ when one of the five possible cases emerges should be found according to Table 1 where $f_{n}$ is the fundamental frequency of the structure and DLF is dynamic load factor - the Fourier coefficient of the relevant walking harmonic.

Table 1. Theoretical pacing frequency and corresponding dynamic load factor.

\begin{tabular}{c|c|c}
\hline Case № & Equation & $\begin{array}{c}\text { Recommended } \\
\text { DLF value }\end{array}$ \\
\hline № 1 & $f_{p}=f_{n}$ & 0.12 \\
№ 2 & $f_{p}=0.5 f_{n}$ & 0.11 \\
№ 3 & $f_{p}=2 f_{n}$ & 0.1 \\
№ 4 & $f_{p}=2 / 3 f_{n}$ & 0.11 \\
№ 5 & $f_{p}=2 / 5 f_{n}$ & 0.08 \\
\hline
\end{tabular}

Further analysis should be performed for the cases when pacing frequency is in the following range:

$$
1.0 \leq f_{p} \leq 2.3 \text {. }
$$

\section{Step 3: Determine the equivalent number of persons $H_{e q}$}

The highest response of the tower can be reached when a compact group of visitors moves along the height of the structure (Gaile, Radinsh 2013).

Equivalent number of people $\mathrm{H}_{\mathrm{eq}}$ in the group, whose relevant walking harmonic frequency is close to the natural frequency of the structure, should be found according to the following equations:

$$
\begin{aligned}
& H_{e q}^{95 \%}=0.001 m^{3}-0.0353 m^{2}+0.6249 m+0.8453 \\
& H_{e q}^{90 \%}=-0.0035 m^{2}+0.2831 m+1.3419
\end{aligned}
$$

where: $\mathrm{H}_{\mathrm{eq}}{ }^{95 \%}$ - equivalent number of persons in the group with intended probability of $95 \%$ not being exceeded; $\mathrm{H}_{\mathrm{eq}}{ }^{90 \%}$ - equivalent number of persons in the group with intended probability of $90 \%$ not being exceeded; $m$ - real number of visitors.
Step 4: Maximum dynamic force and its application to structure

Maximum force $F_{i}$ from the selected number of tower visitors for harmonic $i$ and the relevant design situation should be applied horizontally at the last stair flight level and is defined as follows:

$$
F_{i}=H_{e q} \cdot G \cdot D L F_{\text {lat or long }}^{i} \sin \left(2 \pi f_{\text {caseNr }}^{i} t\right),
$$

where: $f{ }^{i}$ caseNr -frequency of the walking force harmonic for design situation under consideration,

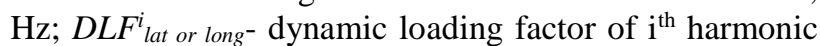
for lateral or longitudinal walking force component; $\mathrm{G}$ - mean weight of the visitor, $\mathrm{N}$.

Load application duration $t$ in second depends on the selected number of subsequent "successive steps" $n$. Simultaneously other four harmonics with relevant frequency according to Table 1 should be applied when fundamental frequency of tower is below $2 \mathrm{~Hz}$.

\section{Step 5: Determine the peak acceleration from applied dynamic loading}

The peak accelerations for the ratio between relevant walking harmonic angular frequency and the fundamental angular frequency $\mathrm{W} / \mathrm{w}_{\mathrm{n}}$ should be determined in the ratio range of $0.8 \leq W / W_{n} \leq 1.2$ to take into account a stochastic nature of the loading. The mean value of peak acceleration $a_{\text {mean }}$ of ratio $z=\mathrm{W} / \mathrm{W}_{\mathrm{n}}$ range can be calculated according to the equation (5):

$$
a_{\text {mean }}=2,5 \int_{0,8}^{1,2} a_{\max }(z) d(z)
$$

where: $a_{\text {mean }}$ - mean peak acceleration, $\mathrm{m} / \mathrm{s}^{2} ; a_{\text {max }}(z)-$ peak acceleration at time $\mathrm{t}, \mathrm{m} / \mathrm{s}^{2} ; \quad z=\mathrm{W} / \mathrm{W}_{i}-$ the ratio between relevant walking harmonic and the excited natural frequency; $t=2 p n / \mathrm{w}_{i}$ - time after $n$ subsequent "successive" steps, s; $w_{i}$ - considered natural frequency of the tower, $\mathrm{rad} / \mathrm{sec}$.

\section{Step 6: Limiting the mean peak acceleration}

The vibration response can be considered satisfactory when the obtained mean peak acceleration multiplied by the weighting factor $W_{d}$ does not exceed a limiting value of $0.2 \mathrm{~m} / \mathrm{s}^{2}$. Weighting factor $W_{d}$ is defined as follows:

$$
W_{d}= \begin{cases}1.0 & \text { for } 1 \mathrm{~Hz}<f<2 \mathrm{~Hz} \\ \frac{2}{f} & \text { for } f \geq 2 \mathrm{~Hz},\end{cases}
$$

where: $f$ - considered natural frequency of the structure.

A limiting value of $0.2 \mathrm{~m} / \mathrm{s}^{2}$ is only the recommended value (majority of people will perceive motion). It can be further modified by factors that take into account the type and location of the particular structure, the required comfort level or other factors. 


\section{Case study}

A calculation example is presented to serve as a verification of the developed methodology and also practical guide for the peak acceleration calculation of light-weight lattice observation tower response to human induced loads. The further calculated mean peak acceleration compared to the experimentally obtained acceleration in case of 7 visitors ascending the existing steel tower of eccentric structural configuration (located in Dzintari, Latvia) (Fig. 1).

\section{Step 1: To determine the input parameters}

To evaluate the natural frequencies and the critical mode shapes of the existing tower theoretically, a three dimensional finite element model created by the commercial structural analysis software STRAP 12.5 has been used.

The structure consists of the braced inner core with dimensions of $1500 \times 1500 \mathrm{~mm}$, made from tubes with the a cross section of $200 \times 200 \times 8$, and the outer core with dimensions of $4240 \times 4240 \mathrm{~mm}$, made from tubes with a cross section of $140 \times 140 \times 5$. The outer core has no vertical bracing, as it was required by the architectural concept. The inner and outer cores are connected together only by steel stairs. At the level of $33.5 \mathrm{~m}$ there is a platform for sightseers. The total height of the tower is $36.48 \mathrm{~m}$. The platform is placed offset from the central core.
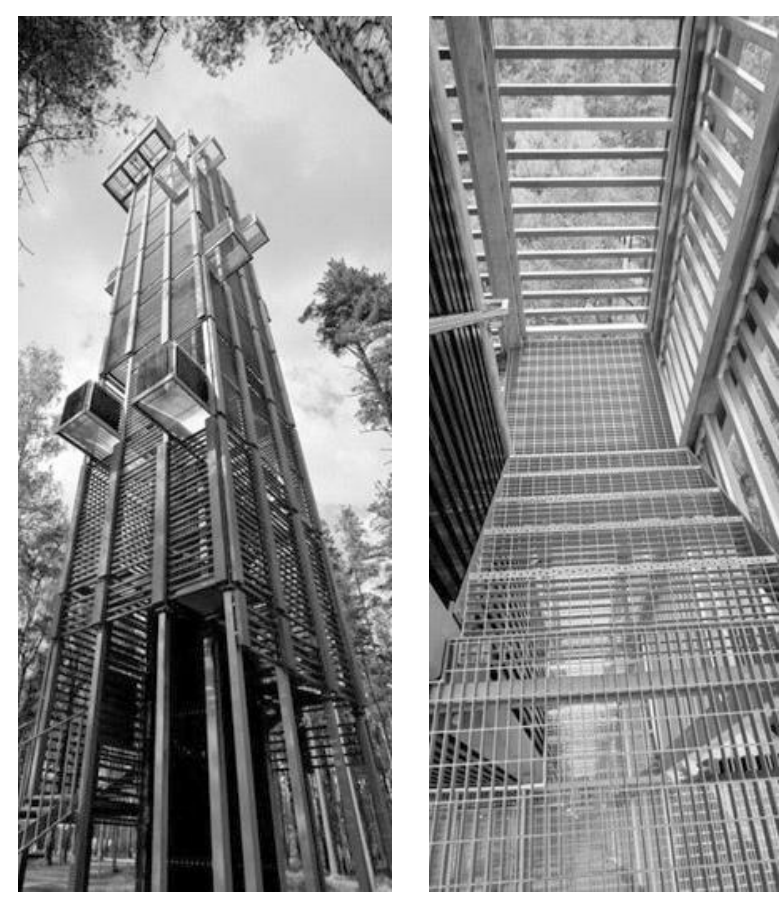

Fig. 1. Observation tower of eccentric structural configuration located in Jurmala, Latvia.

Due to the eccentrically placed visitor's platform mode shape with the lowest frequency is torsional with the centre of rotation outside of the tower's geometry. Mode shapes are not well separated. Fundamental frequency of the tower that was used in calculations was determined from the dynamic testing of structure. The stiffness of the finite element model adjusted accordingly for more precise tower response calculations. Then calculated natural frequencies of the first three mode shapes are as follows:

$-1^{\text {st }}$ mode shape is coupled torsional and flexural with natural frequency of $0.770 \mathrm{~Hz}$;

$-2^{\text {nd }}$ mode shape is first flexural with natural frequency of $0.790 \mathrm{~Hz}$;

$-3^{\text {rd }}$ mode shape is first torsional with natural frequency of $1.157 \mathrm{~Hz}$.

The numerical values obtained from detailed tower 3D modelling are usually upper bonds on frequency because of the effects of connection and foundation flexibility (Madugula 2002). The lattice tower type structure is sensitive to the accuracy of the simulation thus care should be taken when modelling it. In terms of inertia, the various light weight attachments to the tower are not significant if it does not exceed $10 \%$ of the tower weight itself (Khedr 1998), therefore weight of the group of visitors on the tower usually can be neglected.

Also damping ratio is taken from the experimental results: $x=2.3 \%$. The mean weight of visitors is assumed $746 \mathrm{~N}$ and weight of the tower is calculated $720 \mathrm{~kg} / \mathrm{m}$. Number of subsequent "successive steps" $n$ is taken as four (recommended value in previous researches of the paper authors).

\section{Step 2: To determine the most possible design situations}

The possible design situations are analysed in Table 2 by finding pacing frequency when one of the walking harmonics coincides with the fundamental frequency of the tower.

Table 2. Design situation analysis.

\begin{tabular}{|c|c|c|c|}
\hline $\begin{array}{c}\text { Case } \\
\text { № }\end{array}$ & $\begin{array}{l}\text { Walking } \\
\text { harmonic }\end{array}$ & $\begin{array}{l}\text { Pacing } \\
\text { frequency }\end{array}$ & Notes \\
\hline № 1 & $\begin{array}{l}1^{\text {st }} \\
\text { longitudinal }\end{array}$ & $f_{p}=0.76 \mathrm{~Hz}$ & $\begin{array}{l}\text { Small probability } \\
\text { (pacing too slow) }\end{array}$ \\
\hline № 2 & $\begin{array}{l}2^{\text {nd }} \\
\text { longitudinal }\end{array}$ & $\begin{array}{l}f_{p}=0.76 / 2=0.38 \\
H z\end{array}$ & $\begin{array}{l}\text { Impossible (pacing } \\
\text { too slow) }\end{array}$ \\
\hline № 3 & $1^{\text {st }}$ lateral & $\begin{array}{l}f_{p}=0.76 \cdot 2=1.52 \\
H z\end{array}$ & Should be checked \\
\hline № 4 & $3^{\text {rd }}$ lateral & $\begin{array}{l}f_{p}=0.76 \cdot 2 / 3= \\
0.51 \mathrm{~Hz}\end{array}$ & $\begin{array}{l}\text { Small probability } \\
\text { (pacing too slow) }\end{array}$ \\
\hline № 5 & $5^{\text {th }}$ lateral & $\begin{array}{l}f_{p}=0.76 \cdot 2 / 5= \\
0.3 \mathrm{~Hz}\end{array}$ & $\begin{array}{c}\text { Impossible (pacing } \\
\text { too slow) }\end{array}$ \\
\hline
\end{tabular}

Analysis reveals that most likely case № 3 will realize when 1st harmonic of lateral force component coincides with the fundamental frequency of structure. Due to the specific character of the structure and fundamental frequency well below $2 \mathrm{~Hz}$ the rest of the harmonics also should be applied to the finite element model simultaneously. The advantage of using finite element calculation is that all relevant walking harmonics can be applied at once. 


\section{Step 3: Determine the equivalent number of persons $H_{e q}$}

The next step is to find the equivalent number of persons $\mathrm{H}_{\mathrm{eq}}$ in the group, whose walking frequency is close to the fundamental frequency of structure (equations (2) and (3)):

$$
\begin{aligned}
& H_{e q}^{95 \%}=0.001 m^{3}-0.0353 m^{2}+0.6249 m+0.845= \\
& =0.001 \cdot 7^{3}-0.0353 \cdot 7^{2}+0.6249 \cdot 7+0.845=3.83 \\
& H_{e q}^{90 \%}=-0.0035 m^{2}+0.2831 m+1.3419= \\
& =-0.0035 \cdot 7^{2}+0.2831 \cdot 7+1.3419=3.15
\end{aligned}
$$

Step 4: Maximum dynamic force and its application to structure

Maximum force of each harmonic from a group of 7 people with intended probability of $95 \%$ not being exceeded applied to the last flight of stairs and according to equation (4):

$$
\begin{gathered}
F_{95 \%}^{1}=H_{e q}^{95 \%} \cdot G \cdot D L F_{\text {long }}^{1}=3.83 \cdot 746 \cdot 0.12=342.9 \mathrm{~N}, \\
F_{95 \%}^{2}=H_{e q}^{95 \%} \cdot G \cdot D L F_{\text {long }}^{2}=3.83 \cdot 746 \cdot 0.11=314.3 \mathrm{~N}, \\
F_{95 \%}^{1}=H_{e q}^{95 \%} \cdot G \cdot D L F_{\text {lat }}^{1}=3.83 \cdot 746 \cdot 0.1=285.7 \mathrm{~N}, \\
F_{95 \%}^{3}=H_{e q}^{95 \%} \cdot G \cdot D L F_{\text {lat }}^{3}=3.83 \cdot 746 \cdot 0.11=314.3 \mathrm{~N}, \\
F_{95 \%}^{5}=H_{e q}^{95 \%} \cdot G \cdot D L F_{\text {lat }}^{5}=3.83 \cdot 746 \cdot 0.08=228.6 \mathrm{~N} .
\end{gathered}
$$

Each load $F_{95 \%}^{1}$ is applied horizontally in the appropriate direction and changes according to the sine wave: $\sin \left(2 \pi f_{\text {caseNr } 3}^{i} t\right)$.

Load application duration $t$ in seconds depends on the selected number of subsequent "successive steps" $n$ :

$$
t=\frac{n}{f_{p}},
$$

For example, the peak value of tower tip acceleration should be found at time interval $t$ if the angular frequency ratio of $\mathrm{W}^{1}{ }_{\text {lat }} / w_{n}=0.8$ is considered:

$t=\frac{n}{f_{p}}=\frac{4}{0.616}=6.492$.

\section{Step 5: Determine the peak acceleration from applied dynamic loading}

Calculated values for the ratio between relevant walking harmonic angular frequency and the fundamental angular frequency $W^{l} l a t / W_{n}$ in the ratio range of $0.8 \leq W / w_{n} \leq 1.2$ are presented in the Table 3 .

The rest of the harmonics were also applied to the finite element model with the relevant loading frequency according to Table 1 to get peak acceleration $a_{\max }(t)$.

Calculated peak acceleration values demonstrate that maximum acceleration amplitude isn't necessarily reached when loading frequency of particular case is matched exactly with the fundamental frequency of the structure. The ratio range $z$ covers also other poorly separated natural frequencies of the structure. As well as a different energy input of the rest of walking harmonics to the total vibration of the structure has been taken into account.

Table 3. Peak acceleration with intended probability of $95 \%$ not being exceeded from $1^{\text {st }}$ lateral walking force harmonic.

\begin{tabular}{c|c|c|c|c}
\hline № & $\begin{array}{c}\text { Loading } \\
\text { frequency } \\
f_{p} / 2,\end{array}$ & $\begin{array}{c}\text { Ratio of } \\
\text { angular } \\
\text { frequencies } \\
\Omega_{\text {lat }}^{1}\end{array}$ & $\begin{array}{c}\text { Peak } \\
\text { acceleration at } \\
\text { time interval } t \\
a_{\max }(z), \\
\mathrm{m} / \mathrm{s}^{2}\end{array}$ & $\begin{array}{c}\text { Time after } n \\
\text { subsequent } \\
\text { "successive" } \\
\text { steps, s }\end{array}$ \\
\hline 1 & 0.616 & 0.8 & 0.4085 & 6.492 \\
2 & 0.654 & 0.85 & 0.3851 & 6.110 \\
3 & 0.693 & 0.9 & 0.3840 & 5.771 \\
4 & 0.731 & 0.95 & 0.3895 & 5.467 \\
5 & 0.747 & 0.97 & 0.3802 & 5.354 \\
6 & 0.762 & 0.99 & 0.3919 & 5.246 \\
7 & 0.770 & 1 & 0.3978 & 5.194 \\
8 & 0.786 & 1.02 & 0.4140 & 5.092 \\
9 & 0.809 & 1.05 & 0.4374 & 4.947 \\
10 & 0.847 & 1.1 & 0.3905 & 4.722 \\
11 & 0.886 & 1.15 & 0.2890 & 4.516 \\
12 & 0.924 & 1.2 & 0.2754 & 4.328 \\
\hline
\end{tabular}

Then the peak acceleration mean value in the ratio range of $0.8 \leq \mathrm{W} / \mathrm{W}_{\mathrm{n}} \leq 1.2$ with intended probability of $95 \%$ not being exceeded can be calculated according to the equation (5):

$a_{\text {mean }}^{95 \%}=2,5 \int_{0,8}^{1,2} a_{\max }(z) d(z)=0.39 \mathrm{~m} / \mathrm{s}^{2}$.

Ratio between the equivalent number of persons with intended probability of $95 \%$ and $90 \%$ not being exceeded according to step 3 is:

$r=\frac{H_{e q}^{95 \%}}{H_{e q}^{90 \%}}=\frac{3.83}{3.15}=1.216$.

Thus calculated peak acceleration with intended probability of $90 \%$ not being exceeded is:

$$
a_{\max }^{90 \%}=\frac{a_{\max }^{95 \%}}{r}=\frac{0.39}{1.216}=0.32 \mathrm{~m} / \mathrm{s}^{2} .
$$

\section{Step 6: Limiting the mean peak acceleration}

The vibration response can be considered as satisfactory when the peak acceleration multiplied by the weighting factor $W_{d}$ does not exceed a limiting value of $0.2 \mathrm{~m} / \mathrm{s}^{2}$. In this case the weighting factor $W_{d}=1$ according to (6), therefore peak value of acceleration is considerably more than $0.2 \mathrm{~m} / \mathrm{s}^{2}$.

\section{Comparison of the results}

Theoretically obtained results of observation tower top platform vibration amplitude of peak acceleration were compared with the experimentally obtained acceleration amplitude. The experimental setup, conditions and procedure are described in the previous work of the authors (Gaile, Radinsh 2012a). Comparison of the obtained results is summarized in Table 4. 
Table 4. Comparison of theoretically and experimentally obtained results.

\begin{tabular}{c|c|c|c}
\hline № & $\begin{array}{c}\text { Calculated peak } \\
\text { acceleration }\end{array}$ & $\begin{array}{c}\text { Experimental } \\
\text { peak } \\
\text { acceleration }\end{array}$ & $\frac{a_{\text {exp }}-a}{a_{\text {exp }}} \cdot 100 \%$ \\
\hline 1. & $a_{\text {mean }}^{95 \%}=0.39 m / s^{2}$ \\
2. & $a_{\max }^{90 \%}=0.32 m / s^{2}$ & $a_{\exp }=0.39 m / s^{2}$ & $0.0 \%$ \\
\hline
\end{tabular}

In this case the agreement with the experimental result is exact if the $95 \%$ of intended probability not being exceeded is considered. It is explicable with the fact that during experiment test persons were asked to try to intentionally synchronize their pacing frequency between each other.

The peak value of acceleration is considerably more than limiting $0.2 \mathrm{~m} / \mathrm{s}^{2}$ and people will perceive motion strongly, therefore most of them will feel uncomfortable while visiting the observation tower. The actual complaints from visitors about the tower's excessive vibrations since the tower was opened on May of 2010, confirm it.

\section{Conclusions}

A step by step algorithm has been proposed to calculate light-weight lattice tower dynamic response to typical human induced time varying horizontal loads. The developed algorithm is based on the previous findings about the stochastic nature and magnitude of the human loading, the effect of separate walking harmonics on the total vibration, unfavourable location of loading and critical design situations, typical mode shapes and frequencies of lattice observation towers, the response of the structure induced by a group of people, parameters that mostly influence the structure response to human induced loading and findings about human comfort criteria.

The calculation method is based on the generally accepted design processes for low frequency structures. It is considered the maximum level of the resonant response of the tower that can be induced by a person under repeated footfall. Group loading of the visitors is handled through the use of the equivalent number of persons whose one of the walking frequencies coincides with the natural frequency of the structure. The algorithm was applied to find the peak acceleration amplitudes of actual $36 \mathrm{~m}$ high light-weight lattice public observation tower with eccentric structural configuration. The theoretically obtained peak acceleration was in an excellent agreement with the experimental data.

For the first time use of the developed calculation algorithm provides a possibility to assess the actual maximum vibration acceleration level produced by the movement of tower visitors and compare it to the limiting acceleration value that ensures fulfilment of serviceability limit state requirements. It allows setting a limit on the number of tower visitors that is justified by the calculations or altering the structural arrangement during the design stage if required.

\section{References}

Catbas, F. C.; Gul, M.; Sazak, H. O., 2010. Dynamic Testing and Analysis of a Football Stadium. In Proceedings of the IMAC - XXVIII. Dynamics of Civil Structures. 2010, Florida USA, Jacksonville, 4, pp. 195-203.

Dougill, J. W.; Blakeborough, A.; Cooper, P. et. al., 2008. Dynamic performance requirements for permanent grandstands subject to crowd action: Recommendations for management, design and assessment. London. Institution of Structural Engineers, $54 \mathrm{p}$.

Feldmann, M.; Heynemeyer, Ch.; Butz, Chr. et. al., 2004. Design of floor structures for human induced vibrations. JRC Scientific and Technical Report. EUR 24084 EN, 64 p.

Gaile, L.; Radinsh, I., 2012a. Eccentric lattice tower response to human induced dynamic loads. In Proc. of the 19th International Congress on Sound and Vibration 2012, pp. 1139-1146.

Gaile, L.; Radinsh, I., 2012b. Human Induced Dynamic Loading on Stairs. In Proceedings of International Conference on Civil and Construction (ICSCE 2012), Stockholm, 2012, 67, pp. 626-632.

Gaile, L., 2013. Analysis of Dynamic Parameters of Observation Towers in Latvia. In Proceedings of the 9th International Scientific and Practical Conference: Environment, Technology, Resources, Latvia, Rezekne, 20.-22. June, pp. 58.-64.

Gaile, L.; Radinsh, I., 2013. Lattice tower dynamic performance under human induced dynamic loads. In Proceedings of the 11th International Conference: RASD 2013: Recent Advances in Structural Dynamics, Italy, Piza, 1-3 July, 2013, pp. 1-15.

Gronley, J. K.; Perry, J., 1984. Gait analysis techniques. Physical Therapy, 63, pp.1831-1838.

Kerr, S. C.; Bishop, N. W. M., 2001. Human induced loading on flexible staircases. Engineering Structures, 23, pp. 37-45. http://dx.doi.org/10.1016/S0141-0296(00)00020-1

Khedr, M. A., 1998. Seismic Analysis of Lattice Towers. Ph. D. Thesis. Department of Civil Engineering and Applied Mechanics. McGill University. Montreal, Canada, 242 p.

Madugula, M. K. S., 2002. Dynamic Response of Lattice Towers and Guyed Masts. American Society of Structural Engineers, US. 257p.

Živanović, S.; Pavic, A.; Reynolds, P., 2005. Vibration serviceability of footbridges under human-induced excitation: A literature review. Journal of Sound and Vibration, 279(1-2), pp.1-74.

http://dx.doi.org/10.1016/j.jsv.2004.01.019

\section{Acknowledgements}

This work has been supported by the European Social Fund within the project "Support for the implementation of doctoral studies at Riga Technical University". 